\title{
Video-Assisted Thoracoscopic Thymectomy Langerhans Cell Histiocytosis
}

\author{
Joseph C. Fusco, MD \\ Department of Pediatric General and Thoracic Surgery, Children's Hospital of Pittsburgh of UPMC, \\ Pittsburgh, Pennsylvania. \\ E-mail: joseph.fusco@chp.edu
}

\section{Gary Nace, MD}

Department of Pediatric General and Thoracic Surgery, Children's Hospital of Pittsburgh of UPMC, Pittsburgh, Pennsylvania.

Juan L. Calisto, MD

Department of Pediatric General and Thoracic Surgery, Children's Hospital of Pittsburgh of UPMC, Pittsburgh, Pennsylvania.

\section{Marcus M. Malek, MD}

Department of Pediatric General and Thoracic Surgery, Children's Hospital of Pittsburgh of UPMC, Pittsburgh, Pennsylvania.

(c) Mary Ann Liebert, Inc. DOI: 10.1089/vor.2017.0458
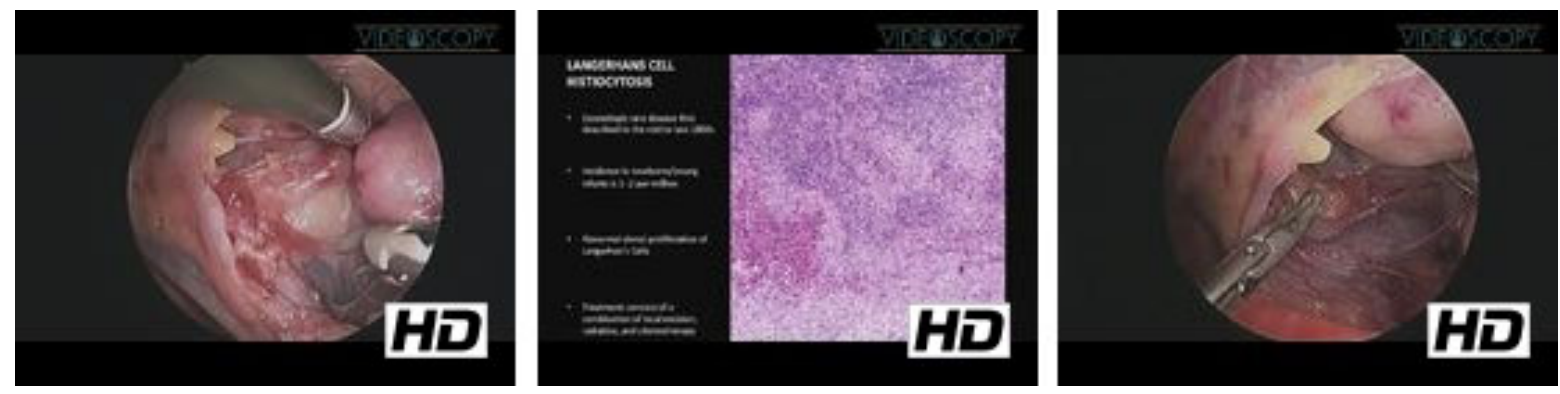

\section{Abstract}

Introduction: Langerhans cell histiocytosis $(\mathrm{LCH})$ is an exceedingly rare proliferative disorder in which pathologic histiocytic cells accumulate in nearly every organ. Although the deposited cells share morphology and antigens with the skin Langerhans cell, the cell of origin is actually a myeloid dendritic cell. LCH is most common in the pediatric population from ages 1 to 3 effecting $\sim 1-2$ patients per million. The most common manifestation of the disease is lytic bone lesions accounting for $77 \%$ of those diagnosed. Lymph nodes and the lung are involved in $19 \%$ and $10 \%$ of cases, respectively.

Methods: Our patient, a 5-month-old, 6-kg female with mild pulmonary valve stenosis, had both thymic and lung tissue involvement. To date, there has never been a report of a thymic LCH with lung metastases in an infant.

Results: She underwent an echocardiogram to assess the degree of her pulmonary stenosis, which incidentally showed a large thymic cyst. That cyst was further characterized with CT scan as a heterogenous mass with multiple lung nodules. The patient was meeting all milestones appropriately and asymptomatic without cardiac symptoms, respiratory difficulty, or feeding issues. To rule out a thymoma, the patient underwent right video-assisted thoracoscopic thymectomy with wedge biopsy of the right lower lobe of the lung.

Conclusion: Final pathology report showed LCH in both tissue samples. The patient did well without complications and was discharged home expeditiously. She is now under the care of the medical oncologists for continued management. 
No competing financial interests exist.

Runtime of video: 4 mins 30 secs

Keywords: Langerhans cell histiocytosis, thymus, video-assisted thoracoscopic thymectomy

\section{Cite this video}

Joseph C. Fusco, Gary Nace, Juan L. Calisto, Marcus M. Malek, Video-Assisted Thoracoscopic Thymectomy Langerhans Cell Histiocytosis, Videoscopy. 2017, DOI: 10.1089/vor.2017.0458.

Original Publication Date: 2017 